\author{
Cadernos de \\ ESTUDOS LINGUIISTICOS - (59.2), Campinas, pp. 317-332 - mai./ago. 2017
}

\title{
MOTIVAÇÃO METAFÓRICA EM UNIDADES FRASEOLÓGICAS ZOÔNIMAS
}

\author{
HELOISA DA CUNHA FONSECA* \\ (UNESP)
}

\begin{abstract}
RESUMO: Este artigo pretende discorrer sobre as questões metafóricas no centro da análise de unidades fraseológicas zoônimas, criadas com nomes de animais, em um estudo contrastivo do português do Brasil e do francês da França. O trabalho aborda principalmente a questão da motivação metafórica que tem sido amplamente discutida, já que parece contradizer o postulado saussuriano da arbitrariedade do signo. Além disso, pela motivação é possível encontrar bases genéricas para as construções metafóricas e, por sua vez, as metáforas congruentes de nível específico que estão intimamente relacionadas à cultura. Para tanto, foram utilizados os construtos teóricos da metáfora conceptual, principalmente por meio dos trabalhos de Kövecses (2010), Lakoff e Johnson (1980) e Sardinha (2007), e também da semântica cognitiva, observando-se os trabalhos de Pamies (2011, 2012) e Mendoza (2001).
\end{abstract}

Palavras-chave: Unidade fraseológica, motivação, cultura.

ABSTRACT: This paper aims to discuss about metaphorical issues at the center of analysis of zoonyms phraseological units, created from animal names, in a contrastive study of the Brazilian Portuguese and the French of France. The paper mainly analyzes the issue of metaphorical motivation that has been widely discussed, since it seems to contradict the saussurian postulate of the arbitrariness of the sign. Furthermore, with the motivation it is possible to find generic bases for the metaphorical constructions and, in turn, the congruent metaphors of specific level that are closely related to the culture. Therefore, the theoretical constructs of the conceptual metaphor were used to achieve this work, especially those concerning Kövecses (2010), Lakoff and Johnson (1980) and Sardinha (2007), and also of cognitive semantics, observing Pamies $(2011,2012)$ and Mendoza's (2001) works.

Keywords: Phraseological unit, motivation, culture.

\section{INTRODUÇÃO}

Alguns aspectos são amplamente utilizados como recursos expressivos de linguagem, sendo dois deles bastante produtivos e recorrentes nas línguas: as unidades fraseológicas e as metáforas. O uso de ambas denota proficiência linguística, uma vez que estão estreitamente relacionadas ao fator cultural. Tanto sua construção como seu emprego obedecem a regras coletivas e compartilhadas por uma comunidade de fala, que mostra, por meio de suas escolhas léxicas, a maneira de captar o mundo e as atividades e fatores humanos que estão imbricados nessa relação.

\footnotetext{
*Universidade Estadual Paulista - heloisaibilce@gmail.com
} 
$\mathrm{O}$ acesso e o aprendizado das estruturas metafóricas fazem parte do desenvolvimento cognitivo comum dos seres humanos que, desde muito pequenos, experienciam fatos da vida que servem de base às metáforas. Esses fatos são exaustivamente repetidos até que passam a constituir e a guiar as ações dos indivíduos.

Exemplifica Lakoff, na conferência para a Commonwealth Club of California em 2008, que a criança sente fisicamente o calor da mãe ao receber abraços e, dessa forma, vai associando "calor" a sentimentos bons e ternos, enquanto a associação de "frio" está para a ordem dos sentimentos negativos; daí decorre o exemplo "ela é uma pessoa fria".

O mesmo ocorre em diversas outras instâncias da vida, como a observação da criança, dia após dia, do preenchimento de compartimentos como um copo ou uma mamadeira, em que é possível observar a relação quantidade e verticalidade, conteúdo e recipiente. Para Lakoff (1987), que relembra os trabalhos de Fillmore (1979), a observação diária desses fatos, por muitas pessoas em várias partes do mundo, gera metáforas do tipo MAIS É PARA CIMA, como em "os preços estão nas alturas".

Com base nisso, alguns autores da semântica cognitiva argumentam que muitas metáforas são motivadas, ao menos em princípio, por atividades concretas e sentidos literários, ou seja, traços visíveis de um mecanismo psicológico subjacente à criação metafórica. Para Kövecses (2010), por exemplo, é possível separar os níveis das metáforas. Segundo ele, alguns traços metafóricos de nível genérico se aproximam da "universalidade" e o nível específico funciona com certo grau de liberdade, são as escolhas feitas por cada língua dentro desse nível genérico.

Contudo, as metáforas não são o único recurso que funciona por meio da observação do mundo e das relações estabelecidas entre fatos do cotidiano e a linguagem; as unidades fraseológicas também desempenham esse papel. Elas surgem de uma necessidade de expressar e intensificar sentimentos e ações que, muitas vezes, não poderiam ser expressos por uma unidade lexical simples. Apesar de muitas unidades fraseológicas corresponderem a lexias simples, como "bater as botas" equivale a "morrer", os fraseologismos podem desencadear efeitos de sentido que as unidades simples não seriam capazes de provocar.

Dessa maneira, pretende-se observar alguns fraseologismos zoônimos, criados a partir de nomes de animais, e as metáforas que os constituem, ressaltando a questão da motivação das metáforas tanto para as unidades fraseológicas do português do Brasil, como para as do francês da França.

Se, por um lado, o conceito de motivação contradiz a arbitrariedade linguística de Saussure (2006), por outro, corrobora a observação de algumas estruturas que, apesar de manterem equivalentes com animais distintos, possuem uma base de criação comum.

Nesse contexto, abordamos alguns conceitos dos principais teóricos dos estudos da Fraseologia e as características do seu objeto de estudo - as unidades fraseológicas, representadas, neste trabalho, apenas pelos conjuntos das expressões idiomáticas (EIs) e dos provérbios. 
Em seguida, serão utilizados os construtos teóricos da semântica cognitiva e da metáfora conceptual, que encontram amparo principalmente em autores como Kövecses (2010), Sardinha (2007), Lakoff e Johnson (1980), e também de estudos sobre a motivação metafórica e de questões culturais que estão estreitamente relacionadas a elas, por meio de Ortiz Alvarez (2009) e Pamies Bertrán (2012, 2011, 2002).

Para finalizar, procedeu-se a uma análise contrastiva, entre o português do Brasil e o francês da França, de algumas estruturas que designam a "embriaguez". Além disso, pretendeu-se separar a metáfora de nível genérico da metáfora de nível específico, em construções zoônimas brasileiras cujos correspondentes em francês são divergentes com relação ao animal de base.

Consideramos que esta breve análise da motivação metafórica possa mostrar como elementos linguísticos estão relacionados a elementos não linguísticos, presentes em nossa vida cotidiana, contribuindo para a compreensão de questões fraseológicas e culturais que, provavelmente, representam dificuldades para o aprendizado de línguas estrangeiras.

\section{FRASEOLOGIAE UNIDADEFRASEOLÓGICA:ALGUNS APONTAMENTOS}

Para compreender melhor o alcance da Fraseologia, é preciso situar outras duas disciplinas científicas: a Lexicografia e a Lexicologia. Se comparada à Lexicografia, a Fraseologia é uma disciplina recente, que remonta à antiga União Soviética, por volta dos anos 40, e que teria como precursor o trabalho de Vonogradov (cf. DOBROVOL'SKIJ, 2012, p. 15). A partir daí, expandiu-se pela Europa e demais continentes, encontrando respaldo na necessidade de estudo das construções pré-fabricadas das diversas línguas naturais.

Grosso modo, a Lexicografia ocupa-se do fazer científico que envolve as teorizações e as técnicas de escansão do léxico, com vistas à produção de dicionários. Paralelamente à Lexicografia, está a Lexicologia, que, de modo geral, seria o estudo teórico das relações do léxico, que dão base aos estudos lexicográficos.

Tendo em vista a relação entre essas áreas de estudo, muitos são os pesquisadores que consideram a Fraseologia uma ramificação da Lexicologia como, por exemplo, Succi (2006) e Rodrigues (2010). Porém, uma vez observada a distinção do objeto e a especificação da teoria, alguns pesquisadores passaram a concebê-la como uma disciplina independente, entre eles Corpas Pastor (2000), González Rey (2004), Olímpio de Oliveira Silva (2007) e MonteiroPlantin (2012).

Para Bally (1951), que classificava a Fraseologia como uma subárea da Lexicologia, a Fraseologia poderia ser dividida em duas outras áreas: uma seria a "Fraseologia popular" que estuda as criações e usos fraseológicos da sociedade, como provérbios, idiomatismos e gírias; e a outra, a "Fraseologia técnico-científica", que se ocuparia das terminologias específicas de certas áreas do saber humano. 
Também Xatara e Parreira (2011,p. 70) salientam “um subconjunto vocabular, que reúne as unidades lexicais complexas, cujo entendimento e descrição compete a uma subárea da Lexicologia, a Fraseologia”. Essas autoras retomam um estudo de Gross (1994) para demonstrar um fato relevante: a presença das unidades complexas em um texto pode chegar à margem dos $60 \%$.

Assim, o conceito de unidade fraseológica, objeto da Fraseologia, encontra grande variedade diante dos autores e suas filiações. Para Corpas Pastor (1996), as características linguísticas mais sobressalentes podem ser assim enumeradas: expressões formadas por mais de uma palavra, institucionalizadas, estáveis e que apresentam particularidades sintáticas e semânticas.

Um aspecto recorrente nas análises dos estudiosos de Fraseologia tem sido a questão da fixidez. Para Zuluaga (1980), os fraseologismos são expressões fixas e produzidas em blocos, frutos de um intenso processo de repetição. O caráter das unidades fraseológicas, dessa forma, constitui "repetição de modelos anteriores [...] mero costume, a tradição continuada e reiterada no falar e no escrever de uma determinada comunidade linguística" (BIDERMAN, 2001, p. 19).

Observando-se diversas definições de variados autores, assim propõe Fonseca (2013, pp. 30-31):

Em resumo, as UFs ou fraseologismos constituem objetos da Fraseologia marcados por seu caráter expressivo, sendo determinados por combinações de duas ou mais unidades lexicais. São um encadeamento fixo ou com certos graus de fixidez estrutural e semântica, cristalizados $\mathrm{e}$, portanto, intimamente relacionados à norma linguística, estabelecendo-se como um ato de língua referente à diacronia e impostos pela comunidade de fala e dependentes de contexto. É importante observar que nem todos os fraseologismos são idiomáticos, e que a idiomaticidade também constitui uma escala gradual.

Apesar de as unidades fraseológicas constituírem o objeto de estudo da Fraseologia, elas podem ser de diversos tipos, dada a variedade de características. Por isso, optou-se por restringir as unidades fraseológicas a serem analisadas neste trabalho. Reunimos EIs e provérbios, por conceber que são categorias de grande importância para o desenvolvimento de competência comunicativa, visto que se valem de uma linguagem amplamente conotada. Entre tantos outros fatores, essas categorias fraseológicas testemunham uma civilização, refletem o conhecimento, o saber linguístico e cultural de um povo em um determinado momento da história.

Assim como as metáforas, as unidades fraseológicas são comuns no uso cotidiano da linguagem, surgem da observação e constatação de situações que envolvem a sociedade como um todo e podem ser empregadas para dar maior expressividade ao que se comunica. Além de demonstrar criatividade linguística, a criação dessas unidades é uma forma de estabelecimento de novos prospectos e modelos mentais acerca do mundo, por meio de estruturas repletas de significação. 
A interlocução, dessa forma, se dá com maior expressividade no contexto em que os interlocutores estão envolvidos. A esse respeito, Camacho (2008) retoma alguns apontamentos de Roncolatto (2001) e assim expõe: "se considerarmos o plano da expressão da linguagem conotativa como um sistema de significação, a conotação pode ser considerada um segundo nível de significação, que se situa além do primeiro significado de uma lexia" (CAMACHO, 2008, p. 20). Dessa forma, a conotação assumiria um outro nível de significado, potencialmente mais abstrato, além do sentido primário e do contexto.

Quando nos referimos às EIs, a conotação anda paralela à cristalização. Rios (2003, p. 39) faz uma análise dessas estruturas e, segundo ela, "o significado idiomático de uma EI, que provém de seu caráter conotativo, só pode ser compreendido se esse for usado da maneira como foi cristalizado. Uma EI é, portanto, a cristalização indecomponível de um uso conotativo". Pode-se perceber, portanto, que uma característica é dependente da outra nas EIs, tanto a cristalização como a conotação estão imbricadas na construção do sentido.

Também nos provérbios é possível observar esses aspectos. Xatara (1998, p. 21) aponta que "aprovado pelo senso comum, o provérbio é um enunciado que utiliza muitas metáforas e sua significação se estabiliza no idioma, pois passou do uso individual para o coletivo". Para esta autora o que difere provérbio de ditados é justamente o sentido literal que estes apresentam.

É importante lembrar que a conotação não pode ser confundida com a metáfora. Como lembra Rios (2003), a conotação é mais abrangente e envolve muitas figuras de linguagem além da metáfora.

No tópico a seguir, pretendemos abordar alguns estudos que se referem às metáforas, explorando como elas podem guiar a forma de pensar das sociedades criando esquemas cognitivos abstratos.

\section{METÁFORAS CONCEPTUAIS: CULTURA E MOTIVAÇÃO}

No senso comum, as metáforas estão amplamente relacionadas ao pensamento poético e literário; são vistas e tratadas como um objeto que se instala fora da linguagem do dia a dia e pertence ao domínio de grandes escritores e pensadores da língua. Entretanto, a metáfora é tão presente na linguagem humana que a maioria das pessoas faz uso desse recurso sem perceber que o estão empregando. Para Gibbs (2002), as metáforas são para os humanos como a água é para os peixes; seria impossível pensar certas expressões da vida cotidiana sem recorrer a elas.

Algumas pessoas, no entanto, fazem uso proposital de tais estruturas com o objetivo de dar maior expressão e força à linguagem, seja falada ou escrita. Utilizam as metáforas como uma forma de persuadir e mostrar domínio sobre determinado assunto, além de estabelecer uma proximidade com o interlocutor (SARDINHA, 2007). 
Para os teóricos das metáforas conceptuais, elas se estabelecem como conceitos na mente. Esses conceitos são socialmente reconhecidos, uma vez que fazem parte do imaginário social e são passados de geração em geração entre os usuários da língua. Nesse sentido, pode-se pensar que as metáforas são uma forma de identificação cultural e linguística, que transparece a maneira pela qual uma comunidade vê e esquematiza o mundo e as atividades que a cercam.

Os estudos a respeito das metáforas conceptuais teriam começado por volta dos anos 70, como o objetivo de mostrar que as metáforas estão vivas e latentes em todas as culturas. Inicialmente, Erving Goffman (1974) disparou as pesquisas sobre os frames. Para ele, cada instituição da vida humana é regida por um frame e os usuários da língua sabem os cenários de cada um desses frames. Dessa forma, quando se pensa em uma floricultura, espera-se encontrar flores, laços, arranjos etc. Se alguém pedir por um quilo de carne em um ambiente de floricultura, claramente, essa pessoa estará agindo fora do frame e o usuário da língua imediatamente reconhece essa quebra.

Seguindo a mesma linha de pensamento, Charles Fillmore (1982) propôs que cada unidade lexical, em cada língua, pode ser definida em termos de frame. Assim, quando dizemos ou escrevemos uma determinada palavra, ela traz consigo um universo conceitual. No entanto, a teoria da metáfora conceptual só ganhou maior visibilidade com a publicação de Metaphors We Live By, livro de George Lakoff e Mark L. Johnson, para os quais as metáforas vão aliar conceitos díspares.

Essa associação entre conceitos, que ocorre intensamente durante a vida, mas principalmente na infância, faz com que dois aspectos distintos como "raiva" e "pressão", por exemplo, sejam cada vez mais relacionados até se tornarem estruturas circulares. Dessa maneira, quando acessamos um desses conceitos o outro é automaticamente ativado nas imagens mentais, possibilitando a criação e o uso da expressão "explodir de raiva”, por exemplo.

Para Cuenca e Hilferty (1999), é preciso observar os campos de ação para determinar as diferenças entre metáfora e metonímia. Essas duas estruturas são tão parecidas porque ambas constituem processos conceptuais que relacionam entidades: "a metáfora associa entidades provenientes de dois domínios distintos (o domínio origem e o domínio destino); a metonímia, ao contrário, associa duas entidades conceptuais contíguas pertencentes ao mesmo domínio" (CUENCA \& HILFERTY, 1999, p. 111).

Nesse contexto, para Lakoff e Johnson (1980), a estrutura das metáforas pode ser dividida e analisada em termos de domínio-fonte e domínio-alvo. O domínio-fonte é aquele que oferece o conceito e o domínio-alvo aquele sobre o qual se supõe determinado conceito. Em "tempo é dinheiro", duas unidades muito diferentes são relacionadas e o tempo, que constitui uma unidade abstrata, passa a ser tratada como o dinheiro, uma unidade concreta. Assim estabelece Sardinha (2007, p. 31), a respeito dos domínios das metáforas:

${ }^{1}$ Tradução nossa, assim como as demais, do original: "la metáfora asocia entidades provenientes de dos dominios distintos (el dominio origen y el dominio destino); la metonimia, por el contrario, asocia dos entidades conceptualmente contiguas pertenecientes al mismo dominio" (CUENCA \& HILFERTY, 1999, p. 111). 
O AMOR É UMA VIAGEM. [...] O domínio-fonte é aquele a partir do qual conceitualizamos alguma coisa metaforicamente; no exemplo, viagem, geralmente é algo concreto, advindo da experiência. O domínio-alvo é aquele que desejamos conceitualizar; esse é o domínio abstrato; no exemplo, o amor. Os domínios podem ser mais amplos (RELAÇÕES AMOROSAS, em vez de AMOR ou DESLOCAMENTOS, em vez de VIAGEM), ou mais específicos (NAMORO ADOLESCENTE, em vez de AMOR ou DIRIGIR UM CARRO NUMA ESTRADA PERIGOSA, em vez de VIAGEM), dependendo da situação. Um mesmo domínio-fonte por servir a vários domínios-alvo; por exemplo, VIAGEM é fonte de conceito de AMOR, mas também de VIDA.

Antes de entrar em quaisquer outros conceitos, e seguindo a linha de pensamento de Cuenca e Hilferty (1999), é preciso estabelecer uma distinção entre o que é "expressão metafórica" e "metáfora conceptual". Segundo os autores, as metáforas conceptuais constituem esquemas abstratos que servem para agrupar as expressões metafóricas. Um exemplo prático é a metáfora conceptual MORRER É PARTIR, que abarcam expressões metafóricas como "nosso amigo nos deixou" e "partiu dessa para melhor". As expressões metafóricas são casos individuais de uma metáfora conceptual.

Poderíamos afirmar, portanto, que as metáforas são representações conceptuais, são abstratas e estão no campo da cognição. Sendo assim, não há verdade absoluta, posto que a teoria das metáforas conceptuais entende as criações metafóricas como o resultado de mapeamentos da realidade tangível e esses mapeamentos mudam de civilização para civilização.

Assim, para Dell'Isola (1998, p. 39), as culturas podem fazer representações diferentes do mundo e, portanto, esquematizar metáforas de diferentes formas: "se grande parte de nosso sistema conceptual é metaforicamente estruturado e se há traços da cultura de um povo no discurso metafórico, pode haver diferença cultural no processo de criação de uma metáfora e na posterior atribuição de sentido a ela".

É inegável o fato de que cada comunidade tem suas singularidades, e que a cultura é determinante nesses aspectos. Mas, o que é cultura? Para Neiva (1997, apud ORTIZ ALVARÉZ, 2009, p. 03), que segue uma linha antropológica, cultura é aquilo que distingue o que é "nosso" do que é "alheio". Para Ortiz Alvarez (2009, p. 03), determinar e conceituar cultura é uma tarefa bastante difícil e depende da visão teórica sob a qual está apoiado o estudo. De maneira geral, "fica claro que a cultura faz parte da vida social, enriquece-a, e cria através da linguagem códigos particulares para cada comunidade de acordo com as características específicas de cada grupo".

Esta autora também retoma Ribeiro (1981) afirmando que cultura é uma herança social, um acervo compartilhado, pode ser concebida como uma ordenação particular de fenômenos que provê modos de existência e meios de expressão. Se a cultura é aquilo que identifica uma comunidade de falantes, é também o que diferencia e distancia comunidades e línguas. Desse modo, as comunidades podem se identificar por meio da língua e não entender as construções linguísticas que fogem aos seus parâmetros de abstração. 
A dificuldade de entendimento surge do fato de que a relação entre as unidades lexicais das línguas não é unívoca. Assim, uma mesma lexia pode ter variações semânticas e pragmáticas. Essa relação entre unidades lexicais acentua-se quando se pensa em linguagem figurada ou construções de mais de uma palavra, como os fraseologismos. De acordo com Strehler:

Formal ou informal, para veicular um significado, o fraseologismo se constrói com unidades lexicais. Essas últimas são entidades já constituídas nas línguas e, quando um fraseologismo aparece num idioma, ele, de certo modo, herda o "conteúdo cultural" das unidades lexicais, isto é, o fraseologismo se constrói com semas inerentes e/ou aferentes das unidades lexicais (STREHLER, 2009, p. 10).

De acordo o autor, as unidades fraseológicas são compostas pelos significados decorrentes de suas unidades lexicais. Dessa forma, algumas nuanças de sentido das lexias simples passam a compor o fraseologismo. O ponto de vista de Strehler (2009) poderia contradizer a noção de não composicionalidade, o que é questão de discussão também da motivação fraseológica.

Como vimos, uma das características das unidades fraseológicas é a fixidez, inclusive semântica, decorrendo disso a afirmação de que algumas unidades fraseológicas, principalmente as EIs, não são composicionais. Em outras palavras, seu significado não decorre da soma de suas partes. Como lembra Gross (1996, p. 154), "uma sequência é fixa do ponto de vista da sintaxe quando ela recusa todas as possibilidades combinatórias ou transformacionais [...] Ela é fixa semanticamente quando o sentido é opaco ou não composicional". ${ }^{2}$ Além disso, a própria definição de metáfora é fundamentada na capacidade de se tomar uma coisa em termos de outra, transportando sentidos.

A semântica cognitiva, então, concebe "a metáfora vista como um fenômeno psicológico - sistemático e universal - de apreensão de um novo conceito por meio da projeção (mapeamento) de um esquema conceptual prévio aos conceitos emergentes"3 (PAMIES, 2002, p. 02). Assim, o debate sobre a equivalência toca diretamente os fraseologismos, que são extremamente ricos em metáforas. Pamies (2002) retoma ainda Mandelblit e Maalej, que discorrem sobre a motivação nos fraseologismos, para lembrar que o sentido literário é um dos primeiros traços visíveis do mecanismo psicológico subjacente que compõe as projeções metafóricas.

\footnotetext{
${ }^{2}$ Une séquence est figée du point de vue syntaxique quand elle refuse toutes les possibilités combinatoires ou transformationnelles [...] Elle est figée sémantiquement quand le sens est opaque ou non compositionnel (GROSS, 1996, p. 154).

3 Metáphore vue en tant que phénomène psychologique - systématique et universel d'appréhension d'un concept nouveau au moyen de la projection (mapping) d'un schéma conceptuel préalable sur les concepts émergents (PAMIES, 2002, p. 02).
} 
Nesse contexto, Kövecses (2005) afirma que a variação metafórica pode surgir entre culturas diferentes, mas também dentro de uma mesma cultura. A variação que ocorre entre culturas distintas é denominada de "congruência", ou seja, as metáforas estabelecem esquemas genéricos com algumas lacunas, que são preenchidas de forma diferente por culturas distintas. Para Kövecses $(2005$, p. 69), "metáforas de nível específico são institucionalizadas pelo nível genérico no sentido de que exibem a mesma estrutura geral". ${ }^{4}$

O segundo processo de variação constitui as metáforas alternativas. Sperandio (2010) assim resume o pensamento de Kövecses (2005) sobre esse processo:

Podemos ter diferenças na área das metáforas conceituais (ou, mais precisamente, na área do DOMÍNIO-FONTE) de que as culturas dispõem para a conceituação de um DOMÍNIO-ALVO particular. Kövecses argumenta que os chineses dividem com os ingleses todos os domínios metafóricos básicos para felicidade: CIMA, CLARIDADE, FUÍDO SOBRE O CONTÊINER. Todavia, os chineses possuem uma metáfora que não se faz presente na língua inglesa: FELICIDADE É FLOR SOBRE O CORAÇÃO.

Sob essa ótica, seria possível deduzir que a criação metafórica é um fenômeno universal e que algumas culturas compartilham as mesmas representações metafóricas, enquanto outras percebem o mundo e criam metáforas de forma diferenciada. A seguir, propomos algumas comparações entre o português do Brasil e o francês da França, observando construções metafóricas comuns e algumas variantes para as duas culturas.

\section{UNIDADES FRASEOLÓGICAS ZOÔNIMAS - PORTUGUÊS E FRANCÊS}

Para esta análise, foi observado o conceito de "embriaguez", por meio da metáfora conceptual EMBRIAGUEZ É UM ANIMAL. Para isso, recolheu-se algumas EIs do francês, ${ }^{5}$ todas construídas a partir de nomes de animais. Em seguida, realizou-se uma observação dos níveis metafóricos, genérico e específico, propostos por Kövecses (2010), de fraseologismos zoônimos, cujo correspondente em francês usa outro animal de base.

Concebemos que, por meio desta análise comparativa, será possível perceber algumas questões relativas à estrutura fraseológica e à cultura das duas línguas, visto que algumas características animais influenciam a escolha lexical e o significado das unidades fraseológicas, por meio das diferentes associações que são estabelecidas. Neste contexto, tem-se:

Expressões idiomáticas (fr.): soûl comme un âne; soûl comme une grive; sôul comme un cochon; sôul (plein) comme une bourrique; plein comme une huître; rond (noir) comme une vache; rond comme un lapin; bourré comme un rat; gelé comme un canard; rond comme un asticot; bourré comme une huître.

\footnotetext{
${ }^{4}$ The specific-level metaphors are instantiations of the generic-level one in the sense that they exhibit the same general structure (KÖVECSES, 2005, p. 69).

${ }^{5}$ Retirados de Pamies (2011).
} 
Expressões idiomáticas (port.): bêbado como um gambá; bêbado como um porco e chamar urubu de meu louro.

$\mathrm{O}$ primeiro aspecto a ser observado diz respeito à produtividade de fraseologismos zoônimos em francês - dez animais distintos -, em comparação com as três unidades fraseológicas zoônimas do português. Obviamente, há outras expressões sinônimas que também designam o estado de embriaguez, porém, como não estão compostas por animais, foram desconsideradas neste trabalho.

Paralelamente, devemos observar a estrutura dos fraseologismos apresentados, pois a maneira como traçamos as correlações entre itens distintos no interior das unidades fraseológicas pode apontar para o tipo de metáfora estabelecida. Como é possível observar, todas os fraseologismos do francês são de matiz comparativa e obedecem à estrutura:

\section{(casa vazia) + como + animal}

A única exceção está entre os fraseologismos do português, "chamar urubu de meu louro", mas que também mantém a máxima de correlação entre elementos distintos - chamar uma coisa de outra. Nas expressões comparativas, a estrutura [adjetivo + modalizador + comparante] se sobressai, como podemos verifica em Xatara (1994, p. 37):

A metáfora-transferida, ou comparação, por sua vez, não possui uma forma predicativa; ela não é uma epífora. Sua característica distintiva é comportar uma prótase, isto é, a primeira parte de uma comparação que corresponde ao que se chama o comparante, e uma apódose, a segunda parte, que é o comparado.

Dessa forma, por mais estranha que a comparação possa parecer, só é possível correlacionar elementos que possam ser comparados, ou seja, que vão permitir uma decodificação de sentido. Todavia, essa relação entre elementos é variável de uma cultura para outra, pois os aspectos que se sobressaem, e que serão usados nos fraseologismos, podem estar relacionados à maneira de se perceber o animal e seu ambiente.

No Brasil, a associação do animal à pessoa embriagada está relacionada às percepções que os paradigmas da comunidade possibilitam. Então, a associação tende a ser feita em observância do forte cheiro do gambá, odor de defesa, e ao estado de vida do porco que, no imaginário coletivo, vive na sujeira e na lama.

Por sua vez, a expressão criada com o zoônimo urubu está ligada ao estado de confusão da pessoa alcoolizada, uma vez que faz um paralelo com "meu louro". Poderíamos supor duas possibilidades de interpretação dessa metáfora visto que "louro" é uma unidade polissêmica, tanto pode representar o zoônimo "papagaio" como aquele que tem "cor clara de cabelo". Independente da escolha que se faça, um urubu, por ter as penas negras, nunca poderia ser confundido com um animal colorido como um papagaio, nem mesmo com o aspecto de uma pessoa loura, pois remete à escuridão, conforme expõe Azevedo (1983, p. 189). 
Como foi discutido, a metáfora pode ser concebida como um fenômeno motivado, pelo menos em princípio. Nesse contexto, o animal em si não poderia ser associado à bebida, já que não faz uso dela, o que nos leva a pensar que algum comportamento ou elemento, que permeia a vida desses animais, é visto em termos de outro. As expressões zoônimas francesas indicam uma grande gama de correlações, como: estado pouco higiênico (cochon), características físicas (vache, lapin, asticot), diminuição da capacidade cognitiva (âne e bourrique), dentre tantas outras possibilidades.

Algumas dessas estruturas estão relacionadas a aspectos da vida humana e à observação das coisas no mundo. Nesse contexto, não é de se estranhar que algumas expressões existam em apenas algumas regiões, devido ao fato das diferenças climáticas e de relevo. No francês, observa-se a expressão soûl comme une grive, que é um exemplo claro desse tipo de especificidade.

Saber um pouco mais a respeito do zoônimo grive, conhecido como "tordo" pelos brasileiros, poderia ajudar no entendimento da metáfora. Ao contrário do que se possa imagina, o grive não é um pássaro francês, mas escocês, que migra para a França no outono procurando por comida e se instala principalmente nas regiões vinícolas. $\mathrm{O}$ tordo tem a característica de se sobrecarregar de comida, uma forma de fazer reservas calóricas, o que pode impossibilitar o voo e, portanto, fazê-lo suscetível a caçadores e predadores.

A dificuldade ou impossibilidade de locomoção é extensível às pessoas alcoolizadas, o que poderia ser estabelecido como o primeiro traço de similitude. Contudo, o aspecto do exagero na ingestão de comida, provavelmente, seria um traço marcante de motivação, pois, paralelamente, as pessoas tendem a ficar embriagadas pela ingestão excessiva de bebida alcoólica. Além disso, o tordo tende a se instalar em regiões ricas em videiras, consumindo muita uva, que é a matéria prima para a produção do vinho.

A comparação repousa, portanto, num uso lógico da analogia; é um raciocínio implícito; a metáfora propriamente dita repousa, por sua vez, num uso puramente semântico da analogia. Enquanto a metáfora é uma aplicação direta de um predicado, a comparação é algo mais, é uma paráfrase que distende a força da atribuição insólita (XATARA, 1994, p. 40).

Com base no uso lógico das analogias, utilizamos o conceito de metáfora congruente de Kövecses (2010) para realizar as análises a seguir. Segundo o autor, por meio da observação das metáforas, seria possível chegar a dois níveis: genérico e específico. Os fraseologismos que seguem não significam embriaguez, mas são correspondentes em significado, além de serem compostos por unidades fraseológicas do português que apresentam correspondente zoônimo em francês, cujo correspondente não é composto pelo mesmo animal.

Expressões idiomáticas (port.): Entregue às moscas

Expressões idiomáticas (fr.): Ravitaillé par les corbeaux

Zoônimos: mosca (mouche) /corbeaux (corvo) 
Base motivada: em nível genérico, é possível perceber que a expressão tem suporte na consequência do abandono ou do desleixo. Dessa forma, as moscas ou os corvos aparecem como o resultado de uma ação anterior, o abandono, que não é retratado na expressão, mas que existe. Após esse período de esquecimento, há o aparecimento dos animais, no plural, na instância específica. A forma de aparecimento e de comportamento desses animais é distinta. As moscas não "retalham" como os corvos fazem, o que acentua a diferença mórfica.

Expressões idiomáticas (port.): Mexer em casa de marimbondo

Expressões idiomáticas (fr.): Donner un coup de pied dans la fourmilière

Zoônimos: marimbondo (frelon) / fourmilière (formigueiro)

Base motivada: o foco do nível genérico, nas duas expressões, está na ação de mexer e chutar algo perigoso, que pode revidar o ataque. O sentido, dessa forma, é complementado em nível específico pelo receptor da ação "caixa de marimbondo" e "formigueiro" que, apesar de distintos, passam o mesmo sentido de animais que vivem um grupo e picam para se defender.

Expressões idiomáticas (port.): Ser uma mosca

Expressões idiomáticas (fr.): Être une petite souris

Zoônimos: mosca (mouche) / souris (camundongo)

Base motivada: a fonte de sentido em nível genérico, nessas expressões, está no tamanho no animal e, portanto, na possibilidade de que passem despercebidos e transitem pelos espaços sem serem notados. Em nível específico, as línguas escolheram animais diferentes e muito distintos entre si. $\mathrm{O}$ francês minimiza ainda mais o tamanho do camundongo pelo uso de petite, o que pode acontecer na variante da expressão brasileira quando se utiliza o diminutivo "mosquinha".

Provérbio (port.): Cada macaco no seu galho

Provérbio (fr.): Chacun son métier et les vaches seront

Zoônimos: macaco (singe) / vaches (vacas)

Base motivada: em nível genérico, pode-se pensar que o ponto de criação da metáfora é a distinção, a separação. O que marca o nível específico, neste caso, é o tipo de divisão, que pode ser de espaços ou tarefas. Os franceses utilizam a separação das tarefas de guardar as vacas, ao passo que os brasileiros fazem uma divisão por espaços, usando galho como o delimitador.

Nos exemplos apresentados, pretendemos aplicar a teoria da metáfora dita universal e da metáfora congruente postulada por Kövecses (2010). Por meio desses estudos é possível identificar o nível genérico que, nos exemplos, foi compartilhado pelo português e pelo francês. Além disso, o nível específico pode ser alcançado fazendo-se uma comparação entre as estruturas correspondentes. 
Pode-se perceber que os estudos de Kövecses (2010) complementam a ideia de motivação sugerida pela semântica cognitiva. No caso deste trabalho, que visou observar as unidades fraseológicas zoônimas, a separação em níveis possibilitou chegar ao que poderia ser considerado como motivação, na data da criação dessas estruturas.

Todavia, é interessante notar que, apesar de as unidades lexicais comporem o sentido das unidades fraseológicas, a ideia de não composição se sustenta no sentido de que, após fixadas, as unidades lexicais não são retomadas para a composição do significado, pois a estrutura passa a significar como bloco. Como preconiza Lakoff (1987, p. 465), “o significado de toda a construção é motivado pelos significados das partes, mas não é computável a partir delas". 6

\section{CONSIDERAÇÕES FINAIS}

Se, por um lado, é possível encontrar traços motivacionais para a criação das metáforas que, nos exemplos utilizados, podem ser observados na base comum que as expressões parecem compartilhar, como a observação humana de que um animal pequeno passa despercebido: por exemplo, uma mosca e um pequeno camundongo, por outro lado, a motivação não é completa, pois há uma gama de outros animais de pequeno porte que poderiam ter sido usados na constituição dessas expressões como: uma aranha, um piolho ou uma borboleta.

Ao mesmo tempo, características como forma e modo de vida dos animais parecem influenciar na escolha desses zoônimos para a constituição dos fraseologismos e o estabelecimento de metáforas. Uma mosca voa mais rapidamente e de forma menos ziguezagueante se comparada a uma borboleta. Por sua vez, a borboleta constitui outra expressão borboletas na barriga / papillons dans l'estomac, que não poderia ser substituída por mosca, nem por camundongo, pois evoca a imagem mental de uma revoada de borboletas, de inquietação.

Durante o decorrer das análises, foi possível perceber que a separação em níveis genérico e específico, pelo menos para os exemplos que foram utilizados nesta amostra, contribuiu para a identificação da base motivada e que, mesmo nos casos de nível específico, em que há uma certa liberdade de escolha, os zoônimos que servem de criação para os fraseologismos são restritos e parecem ser escolhido arbitrariamente. Todavia, essa observação não pode ser estendida a todos os tipos de estruturas metafóricas, visto que usamos uma amostragem pequena e restrita a animais.

Além disso, este artigo buscou deixar ainda mais clara a influência dos modos de vida e da interação do homem com a natureza na constituição da linguagem natural e como a vida em sociedade, aliada a fatos históricos, políticos e geográficos, fixa usos e unidades fraseológicas que são propagadas e repetidas até entrarem para o acervo léxico e cultural das sociedades.

${ }^{6}[\ldots]$ the meaning of the whole construction is motivated by the meanings of the parts, but is not computable from them (Lakoff, 1987, p. 465). 
A afirmação dos cientistas que estudam as metáforas conceptuais, de que elas fazem parte do desenvolvimento humano, parece ser bastante plausível, principalmente se observado o "princípio da exploração de velhos meios para novas funções" (WERNER; KAPLAN, 1963, p. 403, apud HEINE; CLAUDI; HÜNNEMEYER, 1991, p. 28), pois produzimos novos sentidos a partir de estruturas já existentes. Essas unidades constituem o nosso sistema cognitivo e são instantaneamente ativadas no ato comunicativo. No entanto, esse acesso às informações não é natural para indivíduos que, apesar de estarem expostos a uma língua natural, pertencem a outras comunidades de fala.

A tendência é que os falantes ativem as redes associativas as quais estão habituados e que foram estabelecidas no seio de uma cultura específica. A cultura, nesses casos, separa o que é "nosso" do que é do "outro" (SAID, 1996, p. 14). Portanto, para que seja possível entrar na cultura do outro é necessário aprender essas estruturas culturalmente marcadas.

Por fim, a questão não é encontrar a origem das metáforas que compõem os fraseologismos, mas sim perceber como as metáforas ganham vida e como se dá o processo de conotação. É importante recordar como a cultura e os aspectos nãolinguísticos podem influenciar as criações linguísticas e que esses fatos ficam mais evidentes por meio da comparação entre línguas.

\section{REFERÊNCIAS BIBLIOGRÁFICAS}

AZEVEDO, F. F. S. Dicionário analógico da língua portuguesa: ideias afins. Brasília: Coordenada/ Thesaurus, 1983.

BALLY, C. Traité de stylistique française. Paris: Klincksieck. v. 1, 1951.

BIDERMAN, M. T. Teoria lingüística: teoria lexical e lingüística computacional. $2^{\mathrm{a}}$ ed. São Paulo: Martins Fontes. 2001.

CAMACHO, B. F. Estudo comparativo de expressões idiomáticas do português do Brasil e de Portugal e do francês da França e do Canadá. Dissertação de Mestrado, Universidade Estadual Paulista. Instituto de Biociências, Letras e Ciências Exatas. São José do Rio Preto, 2008.

COMMONWEALTH CLUB OF CALIFORNIA, Fora.Tv, San Francisco, 20 jun. 2008. Disponível em: <http://www.youtube.com/watch?v=S_CWBjyIERY>. Acesso em: 15 ago. 2013.

CORPAS PASTOR, G. Manual de fraseologia española, Madrid: Gredos, 1996.

CORPAS PASTOR, G. (ed.). Las lenguas de Europa: estudios de raseología, fraseografía y traducción. Granada: Comares, 2000.

CUENCA, M. J.; HILFERTY, J. Metáfora y metonímia. In: Introduccion a la Lingüística Cognitiva. Barcelona: Ariel, 1999, pp. 97-124.

${ }^{7}$ Principle of the exploitation of old means for novel functions (WERNER; KAPLAN, 1963, p. 403, apud HEINE; CLAUDI; HÜNNEMEYER, 1991, p. 28). 
DELL'ISOLA, R. L. P. A metáfora e seu contexto cultural. In: OLIVEIRA E PAIVA (org.). Metáforas do cotidiano. Belo Horizonte: Ed. do Autor, 1998.

DOBROVOL'SKIJ, D. Phraseology: historical development and theoretical aspects. In.: ORTIZ ALVAREZ, M. L. (org.). Tendências atuais na pesquisa descritiva e aplicada em fraseologia e paremiologia. v.1. Campinas, SP: Pontes Editores, 2012.

FILLMORE, C. J. (et al.). Individual Differences in Language Ability and Language Behavior. New Yourk: Academy Press, p. 85-99, 1979.

FILLMORE, C. J. Frame semantics. In.: The linguistic society of Korea. Linguistics in the morning calm. Korea: Hanshin Publishing Company, 1982

FONSECA, H. C. Fraseologismos zoônimos: elaboração de base de dados português-francês. Dissertação de Mestrado. Programa de Pós-Graduação em Estudos Linguísticos do Instituto de Biociências, Letras e Ciências Exatas da Universidade Estadual Paulista "Júlio de Mesquita Filho", São José do Rio Preto, 2013.

GIBBS, R. W. The Challenge of Cognitive Linguistics. I Conference on Metaphor in Language and Thought. São Paulo: Pontifícia Universidade Católica de São Paulo, 2002.

GOFFMAN, Erving. Frame Analysis: An Essay on the Organization of Experience. New York: Harper \& Row, 1974.

GONZÁLEZ REY, M. I. A Fraseodidáctica: un eido da fraseología aplicada. In: Cadernos de Fraseología Galega 6, 2004, p.113-130.

GROSS, M. Constructing Lexicon-grammars. In: ATKINS, B. T. S.; ZAMPOLLI, A. (eds.) Computational approaches to the lexicon. Oxford: Oxford University Press, 1994.

IÑESTA, E.; PAMIES, A. Fraseología y metáfora. Granada: Método, 2002, ISBN 84-7933-240-9.

KÖVECSES, Z. Metaphor: a pratical introduction, 2. ed. New York: Oxford University Press, 2010.

KÖVECSES, Z. Metaphor in Culture: universality and variation. New York: Cambridge University Press, 2005.

KRAMSCH, C. Context and Culture. In: Languae Teaching. Oxford: Oxford University press, 1993.

LAKOFF, G. Women, fire, and dangerous things. What categories reveal about the mind. The University of Chicago Press, 1987.

LAKOFF, G.; JOHNSON, M. Metaphors We Live By. Chicago: University Press, 1980.

MONTEIRO-PLANTIN, R. S. Fraseologia: era uma vez um Patinho Feio no ensino de língua materna. v.1. Fortaleza: Edições UFC, 2012.

OLÍMPIO DE OLIVEIRA SILVA, M. E. Fraseografía teórica y práctica. Frankfurt am Main, Berlin, Bern, Bruxelles, New York, Oxford, Wien: Peter Lang, 2007.

ORTIZ ALVAREZ, M. L. A motivação metafórica nas expressões idiomáticas como parte do patrimônio cultural dos povos latino-americanos. Contextos. n. 21, v. 1. Santiago, 2009. p. 21-37.

PAMIES, A. Zoo-symbolism and metaphoric competence. In: Szerszunowicz, J.; Yagi, K. (eds.). Focal Issues on Phraseological Studies. Bialystok (Polska): University of Bialystok (Poland) \& Kwansei Gakuin University, Osaka (Japan), 2012, p. 291-314. 
PAMIES, A. Phraseologie et competence metaphorique: universaux cognitifs vs. heritage culturel. In: Kaldieva, S.; Zaharieva, R. (eds.). Linguistic Studies in honour of Prof. Siyka SpasovaMihaylovna. Sofia: Akademichno Izdatelstvo "Prof. Marin Drinov”. 2011.

PAMIES, A. L'Interculturel et les universaux semantiques l'equivalence cognitive en traduction. Ekonomická Fakulta, Universty Mateja Bela v Banskej Bystrici, 2002.

RIBEIRO, D. As Américas e a civilização - processo de formação e causas do desenvolvimento cultural desigual dos povos americanos. (s.1), 1981.

RODRIGUES, G. Estudo sobre as expressões idiomáticas e o uso de dicionários especiais da língua portuguesa no ensino fundamental. Dissertação de Mestrado, Universidade Estadual Paulista. Instituto de Biociências, Letras e Ciências Exatas. São José do Rio Preto, 2010

RONCOLATTO, E. Expressões idiomáticas do português do Brasil e do espanhol da Colômbia: análise, classificação e equivalências. Tese, Filologia e Lingüística Portuguesa, Faculdade de Ciências e Letras, Universidade Estadual Paulista, Assis, 2001.

SAID, E. Cultura e imperialismo. Barcelona: Anagrama, 1996.

SARDINHA, T. B. Metáfora. São Paulo: Parábola Editorial, 2007.

SAUSSURE, F. de. Curso de Lingüística Geral. $2^{\circ}$. ed. São Paulo: Cultrix, 2006.

STREHLER, R. G. Fraseologismos e cultura. Trabalhos de Linguística Aplicada, Campinas, 48 (1), jan.-jun., 2009, pp. 9-21.

SUCCI, T. M. Os provérbios relativos aos sete pecados capitais. Dissertação, Estudos Linguísticos, Instituto de Biociências, Letras e Ciências Exatas da Universidade Estadual Paulista, São José do Rio Preto, 2006.

XATARA, C. M. As expressões idiomáticas de matriz comparativa. Dissertação de Mestrado, Faculdade de Ciências e Letras, Universidade Estadual Paulista, Araraquara, 1994.

XATARA, C. M. A tradução para o português de expressões idiomáticas em francês. 1998. Tese, Faculdade de Ciências e Letras, Universidade Estadual Paulista, Araraquara, 1998.

XATARA, M. C.; PARREIRA, M. C. S. Elaborando um dicionário fraseológico informal: a coleção Xeretando a Linguagem. In.: ORTIZ ALVAREZ, M. L. e UNTERNBAUMEN, E. H. Uma (re)visão da teoria e da pesquisa fraseológicas. Campinas, SP: Pontes Editores, 2011, pp. 77-92.

ZULUAGA, A. Introducción al estudio de las expresiones fijas. Frankfurt a. M.-Bern-Cirencester/ U.K., Studia Románica et Lingüistica, Verlag Peter D. Lang, 1980. 